\title{
A presença oculta do marxismo na Teoria de Relações Internacionais: Rosa Luxemburgo e o primeiro "grande debate"
}

\author{
The hidden presence of marxism in International Relations \\ Theory: Rosa Luxemburg and the first "great debate"
}

DOI: 10.5752/P.2317-773X.2017v5.n3.p5

Miguel Borba de Sá1

Recebido em: 7 de junho de 2017

Aceito em: 21 de fevereiro de 2018

RESUMO

$\mathrm{O}$ artigo trata do primeiro 'Grande Debate' da teoria de Relações Internacionais (RI) a partir de uma perspectiva inovadora: revisitando-o a partir das formulações teóricas e políticas de autores marxistas proeminentes, em especial, os escritos de Rosa Luxemburgo sobre pacifismo e seu envolvimento com movimentos anti-guerra de seu tempo. O objetivo é superar as abordagens que pretenderam denunciar o primeiro 'Grande Debate' como mera invenção retroativa ou puro "mito" (WILSON, 1988). Demonstra-se que o fracasso de tais tentativas pode ser revertido se lançarmos mão de uma abordagem "contextualista" (QUIRK \& VIGNESWARAN, 2004) que justaponha o debate acadêmico ao debate histórico, político, realmente existente nas sociedades européias e norte-americanas no período que envolve as duas guerras mundiais do século XX. Conclui-se que inserção do ponto de vista marxista-luxemburguista sobre a problemática da guerra e da paz, produzida no mesmo momento histórico a que se refere o primeiro 'Grande Debate' de RI, tem o potencial de enfraquecer o poder controlador de agendas que tal discurso tradicionalmente exerceu sobre a disciplina.

Palavras Chave: Teoria de Relações Internacionais. Primeiro Grande Debate. Marxismo. Rosa Luxemburgo.

\section{AbSTRACT}

The article approaches the first "Great Debate" in International Relations theory (IR) from an innovative perspective: revisiting it through the theoretical and political formulations held by preeminent Marxist authors, especially, Rosa Luxemburg's writings on pacifism, together with the experience of their involvement with antiwar movements of those times. The aim is to go beyond approaches that wished to denounce the first "Great Debate" as a mere, retroactive invention or simply a pure "myth" (WILSON, 1988). It demonstrates that the failure of such attempts can be reverted if we deploy a "contextualist approach" (QUIRK \& VIGNESWARAN, 2004), which is able to juxtapose the academic debate to the political, historical one really taking place at European and North-American societies during the inter-war period of the $20^{\text {th }}$ century. It concludes by noting that the insertion of a Marxist-Luxemburgist point of view about the war and peace problematique, developed at the same historical period to which IR's first "Great Debate" refers to, has the potential of weakening the agenda-setting powers that such discourse traditionally exerted on the discipline.

Key Words: International Relations Theory. First Great Debate. Marxism. Rosa Luxemburg. 
2. Para enunciações da versão convencional da evolução baseada nos 'grandes debates', ver Banks (1985) e Lapid (1989); para uma crítica que ainda assim mantém a narrativa estruturada em debates, ver Weaver (1996).

3. A mais detalhada revisão da literatura crítica sobre o primeiro 'grande debate' é, sem dúvida aquela realizada por Quirk \& Vigneswaran (2004). Sua análise do contexto e da tradição que se formou em cima do primeiro 'grande debate' pretende ir além das denúncias já existentes acerca do "mito" do primeiro 'grande debate', como as de Ashworth (2002), Schmidt (1998) e

Wilson (1988). Mas, assim como estes autores críticos, é possível que sua

tática comum de esmiuçar os supostos debates a fim de conferir se de fato ocorreram e cobrar precisão histórica (cronológica) acabe produzindo o efeito oposto ao esperado: reiterar a construção discursiva do "mito" que pretendem desconstruir. Além disto, tal método empiricista dificilmente se acomoda bem numa abordagem crítica, como a que dizem professar. Em face disto, e do fato de que a narrativa calcada em debates continua a ser a dominante no ensino das relações internacionais como os próprios autores reconhecem (Quirk \& Vigneswaran, 2004: 33;

WILSON, 1988:1) é preciso tentar outras estratégias.

4. Para uma emblemática e sintética auto-descrição deste 'grande debate' fundador das Rl, ver a narrativa ainda hoje presente no departamento de Política Internacional da Universidade galesa de Aberystwyth, onde a disciplina oficialmente teria nascido, junto com o primeiro 'grande debate', a partir de 1919, segundo informa o WebSite sobre a história do curso mais famoso

de Rl: Disponível em (Acesso Out/2016): https://www.aber.ac.uk/en/interpol/ about/history/.

5. Para uma elucidativa recopilação de histórias cruzadas de militantes pacifistas de diferentes persuasões, religiões e origens políticas, que muitas vezes acabaram juntando-se nas prisões, antes e durante a $1^{\text {a }}$ Guerra Mundial, por "objeção de consciência" ao conflito ver: Opposing World War One: Courage and Conscience. Published 2013 jointly by Fellowship of Reconciliation, Pax Christi, Peace Pledge Union, Quaker Peace and Social Witness, Women's International League for Peace and Freedom. Há uma versão digital disponível em (Acesso em out/2016): http://www.ppu.org.uk/ OpposingWorldWarOne.pdf
Introdução

O chamado primeiro 'grande debate' da teoria de Relações Internacionais (RI) é o modo mais tradicional de apresentar a origem da disciplina aos que iniciam estudos nesta área (BOOTH, 1991; SMITH, 1995; WEAVER, 1998). Apesar de questionada, a estruturação baseada numa sucessão de 'grandes debates' oriunda de sua versão anglo-americana $^{2}$ segue influente também na comunidade acadêmica de RI no Brasil (GONÇALVES, 2010: 95-103; MESSARI \& NOGUEIRA, 2005, p. 3-8). Esta permanência se explica, em parte, pelo reduzido debate sobre os 'grandes debates', em especial o primeiro deles. Ficamos restritos a uma opção binária entre a descrição convencional ou sua negação completa, sem jamais reexaminá-lo criativamente. Tendo em vista, portanto, que ignorar o primeiro 'grande debate' ou denunciá-lo como puro "mito" (ASHWORTH, 2002; THIES, 2002; SCHIMDT, 1998; WILSON, 1988; 2012; QUIRK \& VIGNESWARAN, 2004) não surtiu o efeito esperado, novas táticas merecem ser testadas ${ }^{3}$. Nesta oportunidade, perseguiremos uma delas: a de resgatar a presença oculta do marxismo neste primeiro 'grande debate' disciplinar.

O 'grande debate' fundador das RI, habitualmente descrito como uma disputa apenas entre idealistas e realistas, versava sobre as questões da paz e da guerra ${ }^{4}$. Travado na conturbada atmosfera das primeiras décadas do século XX, este 'grande debate' foi de fato grande: ele é mais antigo do que geralmente apresentado e aconteceu para além do mundo universitário e estatal. Ele penetrou no bojo das sociedades civis europeias e norte-americana que, anos antes da eclosão da $1^{\text {a }}$ Guerra Mundial, cindiram-se ao meio entre agendas de política externa opostas; uma pacifista, outra belicosa (HOBSBAWM, 1988; 1995).

Naquele contexto, múltiplas vozes tentaram influenciar os rumos de suas sociedades, atuando tanto no campo pacifista como no belicoso. Dentro do pacifismo, não se encontravam somente os idealistas de caráter liberal geralmente descritos nos livros-texto de RI, mas também grupos religiosos como Quakers e Testemunhas de Jeová; organizações de mulheres; intelectuais e artistas de prestígio; além de seções dos movimentos operários e socialistas de então (HOSCHILD, 2011) $)^{5}$. É sobre este último grupo que o presente artigo se debruçará, em busca de compreender como se posicionava diante das questões de guerra e paz de sua época e, com isto, examiná-lo vis-à-vis o primeiro 'grande debate' de RI. Para tanto, resgataremos as ideias e a figura da revolucionária marxista Rosa Luxemburgo, que destacou-se pela atuação intensa no período que antecede ao conflito mundial, quando dedicou-se à campanhas para evitá-lo (BESANCENOT \& LÖWY, 2016), fazendo do primeiro 'grande debate' das RI parte de sua vida pessoal também. Uma que, de acordo com um biógrafo recente, ela viveu "entre o amor e a cólera"; entre a revolução e a guerra (SCHÜTRUMPF, 2015, p. 21).

Primeiro, analisaremos seus textos e formulações sobre a questão do militarismo, que podem ser lidos como uma crítica ao tipo de realpolitik belicista praticada na Alemanha imperial e que, ao conquistar a maioria da opinião pública, propiciou a deflagração das hostilidades em 
1914. Em seguida, continuaremos com Rosa Luxemburgo em sua análise da ameaça de guerra quando esta já era iminente, trazendo à luz seus escritos sobre as crises internacionais e as alianças entre grandes potências, assim como sua participação nas campanhas anti-guerra da Internacional Socialista, onde Luxemburgo teve atuação destacada. Desta forma, a partir de uma abordagem "contextualista" (QUIRK \& VIGNESWARAN, Op. Cit., p. 12-13) espera-se mostrar uma parte da presença oculta do marxismo no primeiro 'grande debate' de RI, de modo a enriquecê-lo, complexificá-lo e, com isto, ajudar no trabalho de despi-lo do poder delimitador de agendas que tradicionalmente exerceu sobre nossa disciplina ${ }^{6}$.

Militarismo: classes sociais, capitalismo e Relações Internacionais.

A crítica ao fenômeno do moderno militarismo ocupa um local privilegiado nas formulações de Rosa Luxemburgo. Para ela, não se trata de um aspecto a mais da dominação capitalista, mas de um dispositivo central que é, ao mesmo tempo, sintoma da força do sistema, de suas contradições e dos riscos que sua expansão engendrava. Em seu famoso ensaio "Reforma social ou Revolução" [1899], Luxemburgo elencava três motivos pelos quais o militarismo tornara-se "indispensável" para a "classe capitalista" de cada grande potência industrial:

\footnotetext{
Em primeiro lugar, como meio de luta para os interesses concorrentes "nacionais" contra outros grupos nacionais; em segundo, como o tipo de investimento mais importante tanto para o capital financeiro quanto industrial; e, em terceiro, como instrumento de dominação interna de classe diante da população trabalhadora - todos esses sendo interesses que, em si, nada têm em comum com o desenvolvimento da economia mundial capitalista ${ }^{7}$. E o que melhor denuncia esse caráter específico do militarismo atual é, primeiro, seu crescimento geral e contínuo em todos os países, por assim dizer, por sua própria propulsão mecânica interna, um fenômeno que ainda era inteiramente desconhecido até poucas décadas; além disso, a inevitabilidade, o fatalismo da próxima explosão entre os Estados inicialmente interessados, apesar de ao mesmo tempo o motivo ser completamente indeterminado, assim como o objeto do conflito e todas as demais circunstâncias. $\mathrm{O}$ militarismo também transformou-se de motor do desenvolvimento capitalista em uma doença capitalista (LUXEMBURGO, 2011f, p. 34) ${ }^{8}$.
}

Luxemburgo se inseria no bojo de uma polêmica interna a seu Partido Social Democrata dos Trabalhadores Alemães (SPD), cujas lideranças principais - como Eduard Bernstein, contra quem o ensaio fora escrito - tendiam ao reformismo dentro da ordem, que incluía o aceite do militarismo e outras "necessidades" do sistema capitalista. Para tanto, além de já alertar para o risco de um conflito entre grandes potências ("fatalismo da explosão entre os Estados") cerca de uma década e meia antes da deflagração da guerra mundial, ela também tocava na discussão daquilo que chamamos em RI de "dilema da segurança" (HERZ, 1950) ao afirmar que a escalada armamentista crescia continuamente "em todos os países (...) por sua própria propulsão mecânica interna”, para em seguida destacar a dialética entre desenvolvimento e enfermidade que caracteriza a contraditória expansão do sistema internacional moderno. No anexo intitulado "Milícia e militarismo" [1899], escrito como resposta aos artigos do dirigente Max Schippel, Luxemburgo expande seu argumento no sentido de questionar a existência de forças armadas permanentes e defende sua
6. 0 objetivo deste artigo é apresentar ao público brasileiro do campo das Rl uma entrada frutífera no universo marxista a partir de uma argumentação que sugere a existência de benefícios teóricos e políticos que tal contato pode proporcionar ao estudioso da política internacional. Não cabe nos propósitos nem no escopo deste artigo, portanto, uma taxonomia ou uma apresentação exaustiva de exemplos da tradição marxista que poderiam ser úteis às $\mathrm{Rl}$ - e menos ainda ingressar nas suas inúmeras divergências internas, apenas mencionadas quando de interesse para a discussão aqui realizada - mas de uma demonstração preliminar baseada em apenas uma autora e um caso, que cumprem assim uma função metonímica (representar a parte pelo todo) na tática analítica aqui empregada. Tal escolha deve-se ao hábito na literatura das RI de apresentar a disciplina por meio de debates e/ou de embates entre "paradigmas" no sentido khuniano (BANKS, 1985), sem que seja necessário sempre esmiuçar as correntes internas do Liberalismo ou do Realismo quando aborda-se tais tradições (dominantes) de pensamento. Segundo Michael Banks (1985), o marxismo teria comparecido somente o terceiro (ou "inter-paradigmático") desta ordem cronológica de debates, versão que pode e deve ser questionada a partir de diferentes hipóteses como, por exemplo, a avançada no presente artigo.

7. Note-se que esta posição era compartilhada por autores idealistas liberais que aparecem como interlocutores típicos dos realistas do $1^{\circ}$ debate, como Norman Angell (2002) [1910] e (1940), que defendia a inutilidade econômica do imperialismo. Ele seguiu debatendo quase pessoalmente contra Carr (2011) por décadas, acusando-0, paradoxalmente, de ter uma visão "derrotista" da participação britânica na $1^{\text {a }}$ guerra (QUIRK, J.; VIGNESWARAN, D. 2004: 16-17). Luxemburgo viria a alterar sua posição a este respeito em seu trabalho posterior $A$ Acumulação do Capital[1912] (1970), onde defende que sem expansão para regiões ainda não capitalistas, ou seja, sem colonialismo e imperialismo, o sistema capitalista em sinão se sustentaria, e não apenas as empresas capitalistas singularmente analisadas, como antes pensava.

8. A fim de permitir a melhor contextualização histórica do pensamento de Rosa Luxemburgo, indicaremos entre colchetes a data da publicação original de cada texto da autora utilizado neste artigo, deixando a indicação da data da publicação brasileira de seus textos escolhidos por Isabel Loureiro (2011) entre parêntesis somente para as citações diretas, nas quais referencia-se a paginação indicada, a fim de facilitar a conferência do leitor na fonte. 
9. "Isegrim" era o pseudônimo usado pelo drigente do SPD alemão Max Schippel em suas publicações nos Sozialistische Monatshefte e na Neue Zeit, órgãos da imprensa operária social-democrata (socialista) da época substituição pelo armamento dos próprios trabalhadores. Ao introduzir uma dimensão de classe social à polêmica, ela mostra como os marxistas, ao mesmo tempo, reproduziam e complexificavam os termos do primeiro 'grande debate' de RI entre uma utopia pacifista "impossível” versus a "indispensabilidade" do aumento das capacidades materiais para atuar no jogo de poder do plano internacional.

\begin{abstract}
De fato, à cruzada de Isegrim-Schippel ${ }^{9}$ contra a reivindicação da milícia e a favor do militarismo subjaz toda uma visão de mundo político-social coerente. O ponto de vista mais geral do qual Schippel parte para sua defesa do militarismo é a convicção da necessidade desse sistema. Ele prova, com todos os argumentos possíveis de natureza técnico-bélica, social e econômica, a indispensabilidade dos exércitos permanentes. E, de fato, de um determinado ponto de vista ele está certo. O exército permanente, o militarismo é, de fato, indispensável - mas para quem? Para as atuais classes dominantes e para os governos de hoje. Mas o que daí decorre senão que, para o atual governo e para as classes dominantes, de seu ponto de vista de classe, a abolição dos exércitos permanentes e a introdução da milícia, isto é, o armamento do povo, aparecerem como algo impossível, algo absurdo? E quando Schippel, por sua vez, também considera a milícia algo igualmente impossível e absurdo, apenas demonstra que em relação à questão do militarismo ele próprio ocupa a posição burguesa, pois observando a questão com os olhos do capitalista ou das classes burguesas (LUXEMBURGO, 1970. p. 90 - itálicos no original).
\end{abstract}

Luxemburgo estava convencida de que, nas condições de sua época, a função desempenhada pelas compras estatais de equipamentos bélicos, assim como a expansão imperialista, eram soluções convenientes para o problema capitalista da superprodução e do excesso de capitais concentrados, em busca incessante por reinvestimento e valorização (LUXEMBURGO, 1970). Portanto, eram necessidades do sistema capitalista e daqueles que dele se beneficiam, mas não de toda a sociedade. Segundo sua análise, ao passo que os gastos bélicos garantiam uma demanda segura e constante, de larga escala e com configuração monopolista de preços - "o negócio mais brilhante para o capital" -, a militarização crescente das sociedades também proporcionava aos capitalistas maior "poder social" frente aos movimentos de trabalhadores (LUXEMBURGO, Op. Citf, p. 96). Daí sua conclusão de que "no militarismo, cristalizam-se o poder e a dominação, tanto do Estado capitalista quanto da classe burguesa", sendo que, por este motivo, "o combate ao militarismo por princípio faz parte da essência da social-democracia”" (LUXEMBURGO, 2011f, p.101 - itálicos no original). O pacifismo socialista toca e se agrega, assim, aos demais pacifismos da época pré-Guerra (HOSCHILD, 2011; MARCOBELLI, 2014).

Em um artigo posterior, intitulado "O que queremos? Comentários sobre o programa da Social-Democracia do Reino da Polônia e Lituânia” [1906], Rosa Luxemburgo (que era polonesa, judia e emigrara para Alemanha após completar seu doutorado em economia, na Suíça) volta a elaborar criticamente sobre a relação entre lutas de classes, questão nacional, militarização e guerras, entrando novamente no terreno dos temas mais caros às RI e seus 'grandes debates'.

O desenvolvimento industrial colocou sob seu domínio praticamente todos os países da Europa, a América do Norte e a Austrália, e penetrou na Ásia e no interior da África. Ele também aumenta a miséria e insatisfação das classes trabalhadoras em todo o mundo, entre todas as nações. O capitalismo é uma praga internacional da humanidade e, também por isso, os trabalhadores devem agir em conjunto e da mesma forma contra o lucro. Não será possível lograr a dominação do capitalismo 
e a derrubada da propriedade privada apenas num país qualquer, independente de outros. Somente ao mesmo tempo em todos os países onde funcionam as chaminés fabris, onde a miséria vive na casa dos trabalhadores, é que estes podem, em conjunto, concretizar a sublevação socialista. Karl Marx e Friedrich Engels encerraram, em 1847, o seu Manifesto Comunista, com o brado: "Proletários de todos os paises, uni-vos!" Com isso em mente, a social-democracia é um partido internacional. Seu objetivo é a união dos trabalhadores de todas as nacionalidades e países em um Exército, que luta por um futuro melhor para a humanidade (LUXEMBURGO, 2011e. pp. 211-212 - itálicos no original)

Percebe-se, por este posicionamento, que os temas da guerra e da paz continuam centrais para os marxistas no mesmo instante em que também o são para o nascimento da disciplina de RI, em especial, a partir de seu primeiro 'grande debate'. Mas, ao contrário da estreita opção binária entre idealismo e realismo, o marxismo de Luxemburgo preconizava a utilização de aspectos centrais de ambos, ao mesmo tempo em que invertia os termos das discussões sobre a guerra, entendida tradicionalmente como conflito entre Estados-nação, em direção a uma ontologia social cujas categorias centrais eram mais complexas: de um lado, a "humanidade" (e seu exército de trabalhadores); e, de outro, o sistema capitalista, ambos atravessados por Estados-nacionais em cujo seio se enfrentavam classes sociais antagônicas.

Vale notar que em sua análise esse papel do militarismo é descrito não apenas em seus aspectos mais especificamente marciais, econômicos ou geopolíticos, mas também na forma de um ethos cultural e de uma ideologia que dobrava a consciência das massas, fazendo-as atuar em uma direção contrária a seus próprios interesses e origem social. Ao fazê-lo, Luxemburgo se aproxima bastante daquilo que os idealistas liberais da época, como Angell (2002), apregoavam. Ela descreve, até em seus contornos psicológicos, como a militarização crescente das sociedades estaria relacionada com efeitos políticos deletérios, pessoais e coletivos, para o "povo trabalhador":

O povo trabalhador só tem perdas com o Exército e com as guerras. No Exército permanente, a juventude do povo perde os mais belos anos da vida, para, em vez de trabalhar em seu benefício e de sua família, gastar tempo em treinamentos sem sentido, aguentar uma série de abusos cruéis e humilhações de suboficiais e oficiais brutais. Em uma guerra morrem milhares de filhos do povo, colocando suas vidas como oferenda ou ficando aleijados por toda a vida, para o enriquecimento de seus piores inimigos - os capitalistas. Quase todo o custo de manutenção de um imenso Exército e condução de guerras cai sobre as costas desse mesmo povo. Os incontáveis milhões, que o governo desperdiça para os quartéis, canhões, navios de guerra, oficiais etc., não saem de nenhum outro lugar que não dos bolsos do povo comum. Os impostos, pagos por esta mesma massa pobre, para cada pedaço de alimento colocado em suas bocas, e de cada linha das roupas de seus corpos, são esta fonte, da qual cada governo dos dias de hoje mantém o militarismo. Mas o maior prejuízo causado à classe trabalhadora é que o Exército é uma ferramenta de opressão do povo pelo próprio governo, em seu próprio país! É verdade que no Exército serve este mesmo povo trabalhador. O soldado é este mesmo trabalhador e camponês de uniforme. Mas os vários anos de serviço militar nos quartéis, afastados da família e dos amigos, e a disciplina terrível no Exército são arranjados de propósito para fazer deste trabalhador e camponês uma fera desnorteada, cega e surda para tudo aquilo que não sejam as ordens seus comandantes. Depois de alguns anos de treinamento, o soldado esquece que é filho do povo, para completamente de pensar no que faz, torna-se capaz de matar pai e mãe, caso ordenado pelos oficiais. E então as classes e governos dominantes têm no Exército uma arma assassina contra os trabalhadores conscientes e camponeses em revolta (LUXEMBURGO, Op. Cit., pp. 244-245). 
10. Para acessar o vídeo com a íntegra do pronunciamento de Dwight Eisenhower alertando sobre o risco representado pelo que chamou de "complexo industrial-militar" em seu discurso de despedida da presidência dos norte-americana em 1961, ver (Acesso out/2016): https://www.youtube.com/watch?v=CWilYW_fBfY.
A seu modo, então, os marxistas interferiam no primeiro 'grande debate' e, quando logravam, também nas decisões políticas de estadistas onde o movimento socialista era forte o suficiente para influenciar a política externa de seus governos no pré-Primeira Guerra Mundial. Isto acontecia quando conseguiam desmascarar os interesses do 'partido da guerra' em cada sociedade perante os olhos das suas opiniões públicas, a partir de argumentos como este de Luxemburgo, a seguir, que, dentre outras contribuições, já elaborava pioneiramente sobre as engrenagens daquilo que posteriormente chamar-se-ia de 'complexo industrial-militar' ${ }^{\prime 10}$ :

as guerras, que as nações hoje conduzem entre si, não são necessárias para a classe trabalhadora, só para os capitalistas. A classe trabalhadora não tem nenhuma vantagem no fato de o país conseguir novas terras, vencer países e povos estrangeiros, que pode roubar e oprimir. A vantagem disso é somente dos capitalistas, que obtém novos mercados, nos quais podem gastar e trocar por outro, por meio do trabalho sangrento arrancado dos trabalhadores. A nobreza igualmente se aproveita do Exército e das guerras, ocupando os níveis mais altos no Exército, e encontrando, deste modo, uma oportunidade para uma vida de ócio e para receberem bons soldos do caixa do Estado. Por fim, os altos e baixos funcionários encontram na guerra e nos países recém-conquistados a possibilidade de enriquecer com o dinheiro roubado, em detrimento dos soldados famintos e da humilhada população vencida. Agora, quem obtém a maior vantagem de armamentos, grandes Exércitos e condução de guerras são os fabricantes de ferro, aço, canhões, armas e tanques, e também os diferentes fornecedores de uniformes e produtos alimentícios para o Exército. Centenas de milhões por ano, gastos para a manutenção do Exército, viajam desta forma do caixa do governo para o bolso de um punhado de capitalistas, os quais, particularmente durante as guerras, constroem imensas fortunas, enquanto o país, ao perder seus tanques, armas e canhões durante as batalhas, precisa cada vez mais de instrumentos assassinos (LUXEMBURGO, 2011e, p. 244 - grifo nosso ).

Em suma, diante da escalada de tensões vivida nos anos que precederam à $1^{\text {a }}$ Guerra Mundial, autores marxistas e militantes socialistas como Rosa Luxemburgo esforçavam-se para fazer ecoar seu diagnóstico teórico e político sobre a natureza do conflito que se avizinhava e as maneiras de evitá-lo. Os marxistas expunham quem seriam os maiores beneficiários e os principais prejudicados caso o conflito entre a Tríplice Aliança e a Tríplice Entente de fato estourasse. Para o estudante familiarizado com a literatura de RI sobre o primeiro 'grande debate', torna-se quase impossível não perceber que ambos se referem a um conjunto muito similar de questões (teóricas, econômicas, geopolíticas e militares) envolvidos numa mesma problemática, aquela que versa sobre guerra e paz, num mesmo contexto histórico e geográfico: a Europa da Belle Époque. Mais ainda, os marxistas faziam suas análises teóricas bastante interessados nas decisões dos policy-makers em cada conjuntura concreta, outra característica que Quirk \& Vigneswaran (Op. Cit.) identificam como distintiva do primeiro 'grande debate' em relação aos subsequentes. Só que em vez das conhecidas opções realistas e idealistas, surge uma terceira postura, que soma-se ao debate, incrementando-o a partir da introdução de novas ontologias (de classe), novos métodos (dialética) e, por fim, novas preocupações normativas (emancipação da exploração estatal-capitalista). 
Crises imperialistas e debates na Internacional Socialista:

Rosa Luxemburgo no banco dos réus.

Em 02 de Julho de 1911 o governo alemão envia o navio-canhoneiro "Panther" para o porto de Agadir, no Marrocos, provocando imediata reação do governo francês, que pretendia manter aquela região do noroeste da África como sua área de influência exclusiva. Tratava-se de uma nítida provocação germânica, motivada pelo crescimento exponencial de suas forças armadas na década anterior. Era a segunda "Crise Marroquina" envolvendo as duas potências europeias (a primeira ocorrera entre 1905 e 1906) e, assim como a anterior, seria resolvida mediante tratados que redistribuíam entre si "grandes domínios da 'parte negra da terra', que volta e meia foi considerada como 'compensações"', conforme analisava Luxemburgo (2011c, p. 411).

Ela escreve nesta ocasião um artigo intitulado "Marrocos" [1911] no qual tece duras críticas à política exterior das potências imperialistas, alertando para os riscos de uma "guerra homicida" e reclamando da "espera angustiante, para a porta trancada de um quarto onde dois 'homens de Estado' conferenciam entre si - o embaixador francês Cambon e o secretário de Estado alemão Kiderlen-Wächter" (LUXEMBURGO, 2011c, p. 411- 412). Diz ela

\begin{abstract}
uma tempestade imperialista avança pelo mundo capitalista (...) Será que a tempestade vai produzir o raio de uma guerra homicida entre dois continentes? Ou será que tal temporal iminente vai se recolher, revelando-se "apenas" como a pacífica barganha que transmite alguns retalhos do mundo de um punho blindado do militarismo europeu ao outro? Esta é a pergunta que, agora, movimenta milhões de pessoas (...) Guerra ou paz? Marrocos pelo Congo ou Togo pelo Taiti? São perguntas que colocam em jogo a vida ou a morte de milhares, bem como o bem-estar ou o sofrimento de povos inteiros. Por essas respostas, meia dúzia de cavaleiros industriais gananciosos barganha e mede seus comentários políticos, assim como no mercado barganha-se pela carne de cabra ou por cebolas, e os povos civilizados aguardam numa inquietação espantosa, como rebanhos, por uma decisão. Essa é uma imagem de brutalidade tão revoltante e de tão tosca mesquinhez que despertaria o ódio de qualquer um que não estivesse diretamente interessado na negociata (LUXEMBURGO, 2011c, p. 411- 412).
\end{abstract}

Luxemburgo ainda não poderia saber, mas seu diagnóstico estava correto, uma vez que a crise viria a ser resolvida pelo Tratado de Fez (1912) que consagrava a 'troca' das pretensões alemãs sobre o Marrocos - a partir de então um protetorado da França - por territórios cedidos aos germânicos no Congo francês (que passaria a se chamar Camarões) destinados a engrandecer o Império Colonial Alemão. Diante desta crise entre grandes potências, Luxemburgo aproveitava para refletir sobre as relações entre política internacional e doméstica, elaborando argumentos que revelam a proposta marxista de analisar estas duas dimensões políticas (interna e externa) como uma totalidade que dialeticamente se constitui a partir da interação mútua entre uma e outra dimensão: "[n]a questão marroquina expressam-se nitidamente, outra vez, o nexo íntimo entre a política mundial e as condições políticas internas dos Estados" (LUXEMBURGO 2011c, p. 413). Assim, para os que consideram que o marxismo em RI seria uma teoria que privilegiaria apenas o " 2 o nível de análise", ou "segunda imagem”, como sugerido por Waltz (2001, p.125) ${ }^{11}$, Luxemburgo já respondia
11. "Marx and the Marxists represent the fullest development of the second image"(WALTZ, 2001, p.125). Apesar de ser um expoente da disciplina de Rl e haver dedicado-se ao confronto direto com autores e teorias marxistas em sua clássica tese de doutorado (Man, the State and War: a theoretical analysis) originalmente publicada em 1959, Kenneth Waltz não faz nenhuma menção à "grandes debates" ou "Primeiro Debate" em seu longo capítulo intitulado "International Socialism and the Coming of the First World War" (2001, pp.124-158) 
12. Para mais sobre as estratégias liberais pacifistas (e suas contradições), ver Hobsbawm (1988), que traz uma discussão histórica interessante sobre as Conferências e Congressos Mundiais da Paz, assim como iniciativas filantrópicas como o Prêmio Nobel, cujo idealizador (no sentido do idealismo do primeiro grande debate), Alfred Nobel, fez sua fortuna como comerciante e inventor de armas e explosivos, antes de deixar

parte de sua herança para premiar esforços pela paz mundial. Para mais sobre essa controversa figura, apelidada de 'Mercador da Morte' pela imprensa francesa da época, ver matéria recente de Cristiano Dias no Estado de São Paulo, em 09/10/2015. Disponível em versão digital em (Acesso em out/2016):

http://internacional.estadao.com.br/ blogs/dois-dedos-de-historia/o-mercador-da-morte/

13. Para mais sobre o "realismo-utópico" de Carr (2001) ver Booth (1991). antecipadamente que para os marxistas o internacional também explica o nacional, ao declarar que a "mais nova aventura da política mundial está rica de lições para o esclarecimento político do proletariado" (LUXEMBURGO, Op. Cit., p. 412).

A principal lição, segundo sua análise, seria a falsidade dos discursos e tentativas de controle da escalada armamentista levadas a cabo pelos próprios governos dos países imperialistas. "A crise marroquina é, sobretudo, uma sátira implacável da farsa do desarmamento encenada há poucos meses pelos Estados capitalistas e sua burguesia" (LUXEMBURGO, 2011c, p. 412). Indignada, ela também volta-se contra o "coro dos "livre-pensadores" que havia se juntado "de maneira entusiasmada aos tons dessas canções de paz" governamentais que revelar-se-iam inócuas pouco depois. Ou seja, Luxemburgo dialoga diretamente com os idealistas liberais do primeiro 'grande debate' de RI, que advogavam soluções dentro da ordem institucional existente para evitar o choque entre as potências sem, no entanto, questionarem o capitalismo imperialista nem envolverem as massas numa ampla campanha anti-guerra ${ }^{12}$. Na Inglaterra e na França”, defende ela, em termos familiares ao primeiro 'grande debate' de RI, "os homens de Estado e os parlamentos falavam, através de chavões, acerca da necessidade de limitar despesas com as ferramentas homicidas, em substituir a guerra bárbara por formas civilizadas de procedimentos de arbitração" (LUXEMBURGO, 2011c, p. 412-413). Em termos de teoria das RI, trata-se de uma formulação que antecipa parte dos argumentos realistas que Edward Carr (2001) viria a utilizar em 1939 para criticar o idealismo liberal do entre-guerras. Para ambos, Carr e Luxemburgo, a paz dependeria de fatores materiais mais sólidos do que simples proclamações de vontade:

hoje, esses mesmos homens de Estado e parlamentos apoiam uma aventu-
ra político-colonial que leva os povos para muito perto da beira do abismo de
uma guerra mundial, e o coro dos livre-pensadores na Alemanha se entusiasma
igualmente por essa aventura bélica como antes entusiasmava-se pelas declama-
ções de paz. Essa mudança repentina de cena mostra, mais uma vez, que as pro-
postas de desarmamento e os anúncios de paz do mundo capitalista nada mais
são que pintados panos de fundo - que de tempos em tempos podem até caber
nos assuntos da comédia política, mas que são cinicamente deixados de lado
quando o negócio torna-se sério. Esperar quaisquer tendências pacíficas dessa
sociedade capitalista e apoiar-se seriamente sobre elas seria, para o proletariado,
a autoenganação mais ingênua à qual ele poderia sucumbir" (LUXEMBURGO,
2011c., p. 413).

A entrada no primeiro 'grande debate' é profunda, e sem volta. Cinismo versus ingenuidade estruturam o argumento de Luxemburgo, assim como o fazem no debate fundador das RI. Se na crítica ao militarismo (vista na seção anterior) o marxismo de Luxemburgo a aproximava de posições idealistas contrárias à realpolitik conservadora, agora os socialistas radicais preconizavam pioneiramente (antes da teoria de RI supostamente existir) os mesmos postulados ditos realistas que consagrar-se-iam como dominantes na disciplina a partir dos anos 1940 e 1950 - ou, pelo menos, do dito "realismo-utópico" preconizado por Carr $(2001)^{13}$. A prova mais nítida desta participação complexa - porém não menos intensa - no primeiro 'grande debate' de RI advém da crítica frontal ao Liberalismo e sua responsabilização pela débâcle da ordem internacional, exatamente 
por não ter sido capaz de se opor com sucesso ao "militarismo ascendente", realista e conservador. Ou seja, por haver sido o idealismo liberal derrotado temporariamente naquela etapa do primeiro 'grande debate', que já vinha se desenrolando, como se percebe, "há um quarto de século"

não menos, porém, essa responsabilidade recai sobre o lamentável liberalismo, cuja derrocada política gradual há um quarto de século pode ser imediatamente medida pelos enormes empreendi mentos militares. A falha total diante do militarismo ascendente, que pisoteia e pulveriza a democracia, o parlamentarismo e a reforma social, é o último e lastimável fim do liberalismo burguês (LUXEMBURGO, 2011c., p.415).

É possível perceber que Luxemburgo se opõe aos dois lados do primeiro 'grande debate' simultaneamente, engajando-se em uma discussão com ambos e, por isto mesmo, tornando-se parte ativa desta disputa teórica e política que marcou o ambiente social e intelectual de onde surgiu a atual teoria de RI. Para ela, a "compreensão consciente do sentido interno da política mundial e de suas consequências não é, no caso da classe trabalhadora, um filosofar abstrato, mas o fundamento espiritual de uma política ativa" (LUXEMBURGO, 2011c, p. 415). O primeiro 'grande debate', assim, importa muito para os marxistas e para o movimento socialista internacional desde então.

Não apenas a vanguarda organizada do proletariado, mas as camadas mais amplas do povo trabalhador precisam ser mobilizadas para uma tormenta de protestos contra o novo avanço da política mundial capitalista. O único meio eficaz de combater as brutalidades da guerra e da política colonial é a partir da maturidade espiritual e do desejo decidido da classe trabalhadora, da guerra mundial baseada sobre os efeitos nefastos do capital, e transformá-los em uma rebelião de explorados e dominados rumo a realização da paz mundial e da irmandade socialista dos povos (LUXEMBURGO, 2011c, p. 416).

Esta formulação teórica e tática de Luxemburgo, que apregoava mobilizar as massas para a insurreição doméstica caso a guerra internacional estourasse, foi ganhando contornos mais precisos à medida que as hostilidades pareciam se aproximar. Em outro texto do mesmo ano, cujo título é "Novamente a massa e o líder" [1911], ela regozija-se que "[d] e todos os lados chegam notícias sobre as assembleias e manifestações realizadas pelo nosso partido contra a política mundial e o curso tomado pelo Marrocos” (LUXEMBURGO, 2011d. p. 417). Ela também se alegra ao perceber que as "massas populares respondem ao nosso apelo com maior entusiasmo", mas não deixa de demonstrar insatisfação com a hesitação dos dirigentes de seu partido em convocar tais atos, atrasando-os em cerca de dois meses à "ação de protesto dos socialistas franceses e espanhóis [que] estava a todo vapor" desde o início da crise marroquina (LUXEMBURGO, 2011d, p. 417- 418).

É justamente pela disseminação destas ideias e, principalmente, pelo sucesso que a campanha socialista contra a guerra parecia adquirir na Alemanha e outras partes que Rosa Luxemburgo foi presa e julgada pela Câmara Penal de Frankfurt em 20 de Fevereiro de 1914, já em plena agitação de rua entre partidários e opositores do enfrentamento bélico exterior; em pleno primeiro 'grande debate' na prática, por assim dizer. Seu "Discurso de Defesa" [1914] foi transformado em artigo e publicado dois dias depois no periódico Vorwäts da mesma cidade. A acusação contra ela era por haver "incitado desmesuradamente" aos espectadores de 
dois comícios realizados em Setembro do ano anterior a não atirarem em seus irmãos de classe na França e outros países, o que foi usado pela promotoria como uma prova de que Luxemburgo estava sugerindo o "assassinato de chefes militares" alemães por seus próprios soldados. Em sua defesa, além de relembrar os eixos da crítica ao militarismo (vistos na seção 2), ela reitera que aquelas ações de rua nada teriam de ilegais e já se realizavam fazia tempo, como ela mesma recorda ao mencionar um comício na mesma cidade que, em 1910, já atraíra uma multidão calculada entre 6 e 9 mil pessoas, reunidas no Hipódromo de Frankfurt. O que mudara, segundo ela, era a "má consciência social dos exploradores" que, às vésperas da guerra, temiam que houvesse grande insubordinação nas forças armadas diante dos esforços de esclarecimento popular levados a cabo pela campanha antimilitarista (LUXEMBURGO, 2011b, p. 482).

Luxemburgo fez do seu discurso de defesa uma verdadeira aula de história política e, por que não, de relações internacionais, do ponto de vista socialista, para o promotor e a plateia que acompanhava seu julgamento. Seu objetivo era refutar a acusação de conspiração, ao demonstrar que a política por ela praticada era pública, notória e, principalmente, já antiga

o Congresso de Bruxelas da Internacional, no ano de 1868, apontou na ocasião medidas práticas para o impedimento da guerra. Entre outros aspectos, ele afirma em sua resolução: “... que os povos já podem, hoje, reduzir o número de guerras, ao colocarem-se contra aqueles que fazem e declaram guerras; que esse direito cabe a todas as classes trabalhadoras, que são chamadas quase sozinhas para o serviço militar e, por isso, podem, por si próprias, dar-lhe uma sanção; que quanto a isso, está à disposição delas um meio eficaz, legal e imediatamente realizável; que a sociedade, de fato, não poderia viver se a produção fosse interrompida por um tempo maior, que, portanto, os produtores apenas precisariam parar com o trabalho para tornar impossível o andamento pessoal dos governos despóticos; o Congresso da Associação Internacional dos Trabalhadores em Bruxelas declara que protesta unido da maneira mais enérgica contra a guerra e convida todas as seções da associação dos diferentes países, bem como todas as associações de trabalhadores e organizações de trabalhadores, sem distinção, a agir, com o máximo de entusiasmo, para impedir uma guerra entre os povos, que, por tratar-se de uma guerra travada entre produtores, ou seja, entre irmãos e cidadãos, deveria ser vista como uma guerra civil. O Congresso recomenda a todos os trabalhadores que, em especial, deixem o trabalho para o caso de que ecloda uma guerra em seu país” (Primeiro anexo ao Boletim Periódico do Escritório Internacional Socialista, nº 9, p. 2, citado por LUXEMBURGO, 2011b, p. 487-488).

Esta $1^{a}$ Internacional, Associação Internacional dos Trabalhadores (1864-1877), havia sido fundada, dentre outros, pelo próprio Karl Marx, que foi um de seus principais dirigentes até a desarticulação da entidade por conta de desavenças políticas e teóricas com outras correntes, em especial com anarquistas. Mas é das resoluções da $2^{a}$ Internacional (18891916), da qual fazia parte como figura proeminente, que Luxemburgo extrai a maioria de fontes para seu "Discurso de Defesa"

passo por cima de outras numerosas resoluções da antiga Internacional e vou, diretamente, para os congressos da nova Internacional. O Congresso de Zurique de 1893 declara:

"A posição dos trabalhadores em face da guerra está claramente designada pela decisão do Congresso de Bruxelas sobre o militarismo. A social-democracia revolucionária internacional deve, em todos os países, com mobilização de todas as forças, enfrentar os anseios chauvinistas da classe dominante, amarrar de modo cada vez mais forte o laço da solidariedade em torno dos trabalhadores de 
todos os países e trabalhar, de modo incessante, pela liquidação do capitalismo, que dividiu a humanidade em dois Exércitos inimigos e instiga os povos uns contra os outros. Com a superação da dominação de classe, também a guerra desaparece. A derrubada do capitalismo é a paz mundial" (LUXEMBURGO, 2011b, p. 488).

Sem hesitar, ela segue adiante:

O Congresso de Londres de 1896 reivindica: "Apenas a classe trabalhadora pode seriamente ter a vontade e conquistar para si o poder de criar a paz mundial". Por isso ela reivindica: " 1 - A abolição simultânea dos Exércitos permanentes em todos os Estados e a introdução do armamento do povo. $2^{\circ}$ - A instituição de um tribunal arbitral internacional, cujas decisões tenham força de lei. $3^{\circ}$ - Uma decisão definitiva sobre a guerra ou a paz diretamente através do povo, para caso os governos não aceitarem a decisão do tribunal arbitral”.

O Congresso de Paris de 1900 recomenda que especialmente como um meio prático da luta contra o militarismo: "que os partidos socialistas em todo lugar empreendam e exerçam com o maior entusiasmo a educação e a organização da juventude para o fim do combate ao militarismo" (LUXEMBURGO, 2011b, p. 488 - 489).

Rememorando suas vitórias apertadas no Congresso de Stuttgart $(1907)^{14}$, Luxemburgo continua defendendo-se perante o tribunal por haver participado demais do debate sobre guerra ou paz nas relações internacionais de sua época, mediante o compartilhamento da acusação contra si com o restante do movimento socialista transnacional

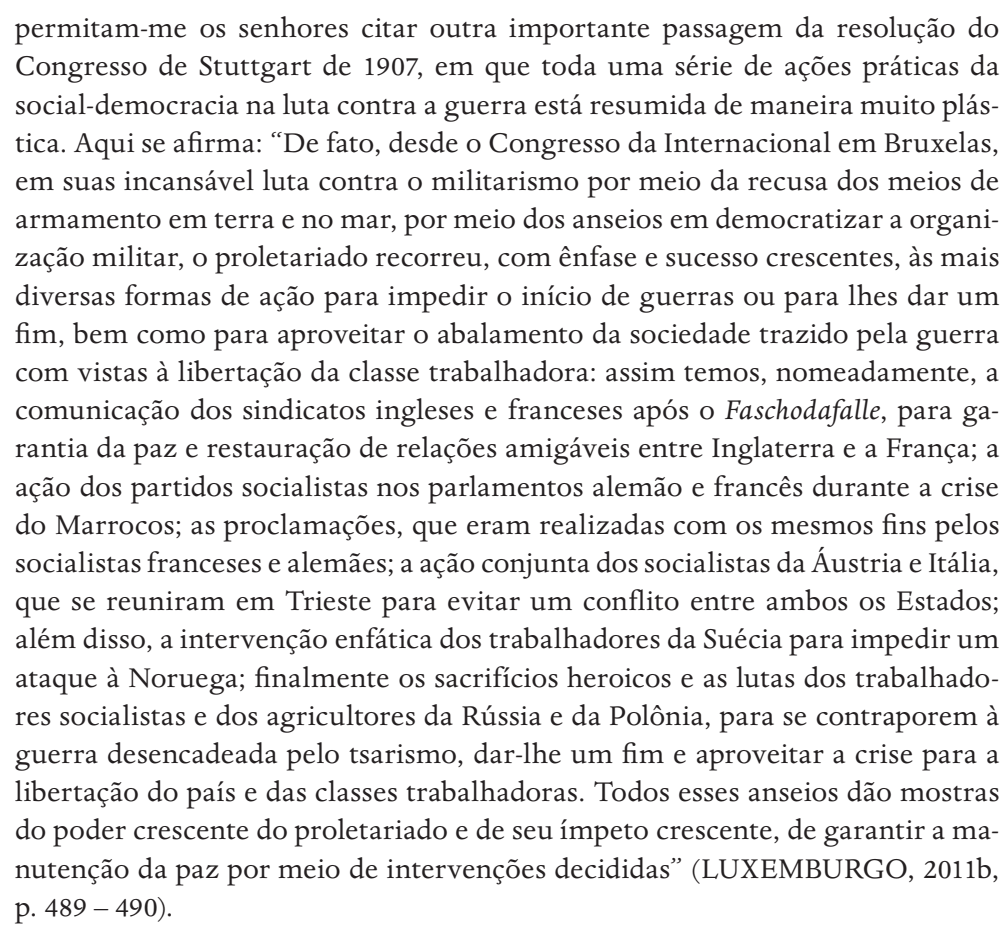

O promotor fecha sua acusação imputando a Luxemburgo a descrição de "grande perigo para a segurança da ordem estatal", qualificando-a como "Rosa vermelha" e pedindo sua detenção por receio de que ela fugisse caso deixada em liberdade (ao que a acusada reagiu com indignação afirmando que "acredito que o senhor fugiria. Um social democrata não foge. Ele reconhece suas ações e ri de suas penas” - LUXEMBURGO, 2011b, p. 492). Condenada, ela ficaria presa de fevereiro de 1915 ao mesmo mês de 1916. Ao participar de uma manifestação contra a guerra em $1^{\circ}$ Maio de 1916, ela é novamente presa "preventivamente" até novembro de
14. Este congresso da Internacional Socialista foi especialmente tumultuado, repleto de impasses e divisões políticas justamente sobre as questões da guerra e do colonialismo europeu, ou seja, sobre as relações internacionais da época. Sobre a guerra, as dissensões deram-se sobre quais medidas tomar em caso de eclosão de conflitos. Além disso, houve delegados que defenderam uma "política colonial socialista" e outros que abertamente professavam seu racismo nos termos mais explícitos. Ao fim, somente conseguiu-se encerrar o congresso após uma profunda costura política liderada por Rosa Luxemburgo e Vladimir Lênin, membros proeminentes da Segunda Internacional, que apresentaram um esboço de resolução capaz de agradar a todos os presentes e, ainda assim, manter os postulados marxistas contra a guerra e 0 imperialismo capitalista (RIDDELL, 2014). 0 episódio também serve para desfazer um mito interno à tradição marxista que, devido ao predomínio mundial do stalinismo durante boa parte do século XX, fazia questão de desqualificar e fazer parecer distantes de Lênin outros autores e figuras de relevo, como a própria Rosa Luxemburgo, Antonio Gramsci e Leon Trotsky, dentre outros. Esta leitura stalinista muitas vezes dá a impressão de que Lênin teria estado mais ao lado de personagens como o reformista Rudolf Hilferding, de quem tomara de empréstimo o termo "capital financeiro" (inexistente em Marx), do que de seus colegas revolucionários acima mencionados. A análise dos congressos da Internacional Socialista ajuda a desfazer esta inversão da realidade operada pelo dogmatismo stalinista, que se beneficiou do hábito disseminado na academia de citar autores e "teses" mesmo sem uma leitura própria e direta dos mesmos, como hoje é possível fazer diante das facilidades de acesso aos textos originais. 0 leitor que se aventurar nesta arqueologia do saber marxista encontrará em textos como 0 Oportunismo e a falência da II Internacional um Lênin [1916] proferindo os maiores insultos aos colegas de Hilferding (Karl Kautsly em especial) ao passo que em diversas oportunidades manifestou sua admiração e respeito por Rosa, a quem considerava 'uma águia entre galinhas', em referência aos dirigentes reformistas do SPD alemão. 
15. Também para o marxismo a aproximação com outro campo de saber pode ser benéfica, uma vez que a incorporação do internacional para além

das receitas marxista-leninistas tem um grande potencial de enriquecer seus debates internos e ajudá-los a optar por táticas políticas mais eficazes dos que aquelas calcadas no nacionalismo metodológico, que segue em voga. Mas os possíveis impactos das RI no marxismo fogem ao escopo deste artigo.
1918 (LOUREIRO, 2011, XIII-XIV). É possível considerar, diante deste episódio, portanto, que o "perigo" sentido pelo promotor caso Luxemburgo fosse deixada livre para seguir no debate sobre guerra e paz é análogo ao perigo sentido pelos narradores do primeiro 'grande debate' da teoria de RI que até hoje parecem temer a incorporação dos autores marxistas e movimentos socialistas, que de fato estiveram tão presentes e influentes com formulações e argumentos tanto idealistas como realistas no ambiente social, político e intelectual em torno das duas guerras mundiais do século XX (HALLIDAY, 1999; HOBSBAWM, 1995).

Relações Internacionais, marxismo, riscos:

como lidar com mitos e presenças ocultas.

Tal ocultação, no entanto, não precisa durar para sempre. O custo de não ter levado mais em consideração os alertas marxistas sobre o choque de imperialismos e guerras mundiais foi alto. Assim como o preço pago pela teorização em RI decorrente da virtual supressão do marxismo desde o primeiro 'grande debate' em diante, uma vez que atrasou em décadas a virada crítica experimentada com antecedência por outras disciplinas menos dominadas por paradigmas positivistas, racionalistas e behavioristas como é nossa "ciência social-social americana", na perspicaz expressão de Stanley Hoffman (1977). Os riscos de não fazê-lo, por conseguinte, são maiores do que aqueles que poderão advir de sua tentativa ${ }^{15}$. Pois, em retrospectiva, é impossível não admirar-se com a retidão demonstrada por marxistas como Luxemburgo que deram suas vidas à luta contra a guerra, sendo igualmente impossível não lamentar que seu diagnóstico político tenha tido menos audiência do que o mundo precisaria para evitar o primeiro grande conflito militar inter-estatal, em escala industrial-capitalista, da História

\footnotetext{
pois o que contribuiu em maior medida para a atual situação de guerra do que o armamentismo descontrolado, os incomensuráveis preparativos que, durante os últimos anos na Alemanha, seguiram de imediato uns aos outros? O que, em sua maior parte, desencadeou os apetites imperialistas no sul da Europa, amontoou o material de combustão, acirrou as oposições do que a intervenção frívola da Alemanha no conflito do Marrocos, que foi o que primeiro motivou a pilhagem italiana e, por conseguinte, desencadeou as guerras balcânicas e, por fim, ajudou a preparar a guerra atual? (LUXEMBURGO, 2011a p. 499).
}

Em 18 de Julho de 1914, três semanas após o assassinato do arquiduque Ferdinando da Áustria, em Sarajevo, por nacionalistas sérvios, Rosa Luxemburgo publicava um curto e inflamado artigo no Socialdemocratische Korrespondenz intitulado "A paz, a Tríplice Aliança e nós” [1914], no qual sintetizava os alertas que ela e outros marxistas estavam proferindo há mais de uma década no âmbito do debate social entre três forças sociais: "o partido do proletariado", o "militarismo chauvinista" e os "espíritos ingênuos" - ou seja, o primeiro 'grande debate' de RI entre marxistas, realistas e idealistas liberais (LUXEMBURGO, 2011a, p. 497-498). Dialogando nominalmente - e simultaneamente - tanto com as teorias do "equilíbrio" de poder internacional como com os "desejos de paz" do "espíritos ingênuos", ela vaticina

os acontecimentos forneceram resultados brilhantes à [formulação] política internacional da social-democracia. Hoje até o cego vê que as corridas armamen- 
tistas incessantes e as apostas imperialistas levaram, com necessidade inexorável, ao resultado acerca do qual o partido do proletariado com consciência de classe havia alertado insistente e incansavelmente: à beira do abismo de uma terrível guerra europeia. Hoje até as camadas do povo que se haviam deixado capturar pela propaganda chauvinistas do militarismo reconhecem, consternadas, que o processo incessante de armamento não era uma garantia de paz, mas uma semente de guerra, com todo seu horror. Justamente o grotesco do motivo imediato que amanhã talvez faça as chamas da guerra inflamarem-se em toda a Europa mostra, da maneira mais nítida, como os Estados imperialistas, em sua deriva cega, provocaram a reação de poderes que, num dado momento, crescerão mais que eles e os arrastarão para o turbilhão. Mostra-se, além disso, com toda a nitidez palpável, o quanto as alianças militaristas - que, de acordo com a mentirosa exposição oficial em que caíam os espíritos ingênuos, deveriam ser os pilares do equilíbrio europeu e da paz - comprovaram ser, pelo contrário, meios mecânicos de arrastar todas as outras potências para um conflito local de dois Estados e, assim, provocar uma guerra mundial;

(...) Se aqueles que há anos brincam descuidadamente com o sangue e os bens de milhões sob o fragor bélico dos sabres e mantiveram acesa a fogueira são agora surpreendidos pelas consequências de suas próprias ações, os milhões de proletários em vigília pela paz mundial não têm nenhum sentimento de solidariedade nem de respeito por esses "desejos de paz” do governo alemão, mas apenas um sentimento de raivosa ironia e de profunda frieza. Afinal, na política o que importam não são os sentimentos e os desejos, mas as ações e suas consequências. Entretanto, no que diz respeito à ação efetiva para a preservação da paz na Europa, a tática dos círculos governantes e a tática do proletariado com consciência de classe dividem-se em diametralmente opostas. Neste momento há dois métodos para proteger a paz europeia (LUXEMBURGO, 2011a, p. 497-499).

Dois métodos, duas táticas; mas não exatamente aquela conhecida opção binária do primeiro 'grande debate' ensinada aos alunos de RI, ainda que a englobe: por um lado, a dos socialistas e demais revolucionários anti-capitalistas e, de outro, a dos idealistas liberais somados aos realipolitkers. Introduzindo o marxismo luxemburguista percebe-se melhor a variação das etapas deste importante debate ocorrido ao longo da "era da guerra total", conforme a chamou Eric Hobsbawm (1995, p. 29-60) em cujo contexto foi travado o primeiro 'grande debate' acadêmico das RI que hoje conhecemos. O marxismo radical de Luxemburgo dialogava criticamente com ambas opções do mainstream político de sua época e lugar: sua teorização sobre política internacional confrontava-se com (i) o idealismo liberal representado pelos "mornos desejos de paz dos governos"; assim como rejeitava (ii) o suposto realismo dos generais alemães e seu "método de expulsar o diabo de guerra russo por meio do belzebu de guerra alemão" (LUXEMBURGO, 2011a, p. 500). A derrota pessoal e política de Luxemburgo e seus adeptos neste embate/debate seria custosa para um espectro bem mais amplo da humanidade do que os círculos socialistas e social-democratas nos quais ela figurava com destaque ímpar. Seu assassinato em 15 de Janeiro de 1919 pelos paramilitares alemães (Freikorps), poucos dias após fundar o Partido Comunista Alemão (KPD), representou o fim precoce de sua carreira política, assim como o começo da turbulenta República de Weimar que terminaria na ascensão dos nazistas ao poder em 1933 e a eclosão da Segunda Guerra Mundial em 1939.

Neste artigo, portanto, procurou-se demonstrar que há uma presença oculta, por assim dizer, do marxismo no primeiro 'grande debate', sobre guerra e paz no século XX, da teoria de Relações Internacionais (RI) a partir dos escritos e posicionamentos políticos da autora e militante revolucioná- 
ria marxista Rosa Luxemburgo, anteriores à eclosão da $1^{\text {a }}$ Guerra Mundial em 1914. Espera-se ter mostrado que o chamado primeiro 'grande debate', familiar aos estudantes de RI, foi de fato um debate social que chacoalhou as sociedades europeias e norte-americanas, mas sua duração antecede os limites temporais a que geralmente é confinado, uma vez que já estava em curso desde os anos finais do século XIX, quando crises geopolíticas entre grandes potencias começaram a se suceder.

Norman Angell (2002), frequentemente mencionado como interlocutor principal de Edward Carr (2001) neste debate fundador, lançou o seu clássico A Grande Ilusão em 1910, portanto antes do conflito estourar em 1914 e do curso de RI em Aberystwyth ser fundado em 1919. Tal questionamento da temporalidade de início do primeiro 'grande debate', já efetuado timidamente por Quirk \& Vigneswaran (Op. Cit.), também serve para aventar a possibilidade de que seu fim usualmente proclamado, com a eclosão da $2^{\text {a }}$ Guerra Mundial e a subseqüente Guerra Fria marcando a vitória realista, não ser tão certo assim, abrindo indagações sobre sua permanência até os dias atuais, conforme proposto recentemente por John Mearsheimer (2005), que palestrou na mesma Aberystwyth sob o título: "E.H. Carr vs. Idealism: the battle rages on".

Com efeito, demonstrou-se que além da temporalidade questionável, o primeiro 'grande debate' realmente existente foi marcado por forças sociais e agendas políticas mais amplas do que a geralmente propalada dicotomia entre idealismo liberal e o realismo sugere. A intervenção de vozes como a de Rosa Luxemburgo mostra como o debate sobre guerra e paz que de fato ocorreu era mais complexo e rico, teórica e politicamente. O mérito de tal agregação de uma corrente teórica a uma duvidosa narrativa calcada em 'grandes debates' consiste em desestruturar sua estrutura semântica por dentro, em vez de seguir questionando sua existência por fora, tática que não fora bem-sucedida até hoje na tarefa de superar a limitação das agendas de pesquisa (e financiamento) em RI a um leque estreito, de modo geral, de abordagens liberais ou realistas e suas variantes mais recentes. Afinal, a ideia de um primeiro 'grande debate' pode ser melhor encarada como uma série de meias-verdades do que uma completa ficção (BOOTH, 1996, p. 328; QUIRK \& VIGNESWARAN, Op. Cit., p. 6).

Por isso, em vez de denunciar que o primeiro 'grande debate' foi simplesmente um "mito" - conforme feito por Peter Wilson em 1988, quem, logo em seguida, tratou de fazer da narrativa dos 'grandes debates' uma carreira - optou-se por uma tática desestabilizadora dos pilares em que se sustentam tradicionalmente as narrativas sobre o primeiro 'grande debate' em RI. Como "toda teoria é para alguém e para algum propósito” (COX, 1981, p. 128) sugerir como incorporar produtivamente o marxismo pode vir a ser insuportável para aqueles que se beneficiam dessa reprodução da narrativa tradicional, ao ponto de levá-los a abandoná-la mais rapidamente caso novas levas de estudantes começarem a ver a presença desocultada dos marxistas do que se insistirmos em simplesmente denunciar a artificialidade dos debates e ignorá-los como "mitos" em nossos esforços analíticos (uma posição curiosa para teóricos críticos, uma vez que dever-se-ia partir da presunção de que todo e qualquer debate em ciências sociais é sempre "artificial" no sentido de ser construído discursivamente 
para atender a agendas políticas do presente, sendo difícil entender como tal acusação pode proceder de terreno pós-positivista). Incomodar seus beneficiários em vez de corrigir as imprecisões de seus vocalizadores, eis a nova tática proposta aqui a fim de mais eficazmente enfrentar os "efeitos de poder" (FOUCAULT, 1979, p.171) dos discursos e saberes científicos sobre o primeiro 'grande debate' de RI.

Conclusão

Por fim, vale lembrar que os marxistas continuaram presentes no debate sobre guerra e paz no período do entre-guerras também, mas isto foge ao escopo do presente artigo. A este respeito, Fred Halliday (1999), ajuda a reforçar a hipótese aqui defendida sobre a intervenção marxista no primeiro 'grande debate' entre os teóricos de RI. Ele considera o marxismo [leninista] como um dos múltiplos "projetos idealistas iniciados depois da Primeira Guerra Mundial” (HALLIDAY, 1999, p. 61-86) Apesar da reticência do autor, que afirma que "até agora, o marxismo não se encaixa confortavelmente em nenhum dos três" grandes debates de RI, Halliday (1999) fornece elementos para pensar maneiras de promover esta acomodação produtivamente, ao ilustrar como as abordagens marxistas dialogam e se constituem por meio de elementos tanto realistas como utópicos, mesmo que suas propostas políticas práticas tenham, ao mesmo tempo, "paralelos surpreendentes" e, claro, diferenças frontais em face das duas outras grandes agendas políticas em ação naquele momento histórico.

$\mathrm{Na}$ obra em que busca a "repensar as Relações Internacionais", Halliday (1999) dedica uma seção inteira ao "marxismo e os três 'grandes debates" das RI” (HALLIDAY, 1999. p. 64-69), confirmando que a presença, geralmente ocultada, do marxismo no primeiro deles pode ser relida, na verdade, como um excesso de participação, uma vez que tanto realismo como idealismo são características centrais do marxismo também.

\footnotetext{
O primeiro ['grande debate'] foi o entre as abordagens "utópicas" e "realistas". Apesar de serem elas mesmas termos artificiais, ambas serviram para estabelecer uma polarização ideológica. Nesta estrutura, o marxismo compartilha elementos das duas: é "utópico" ao postular uma forma alternativa de ordenar a política e introduzir preocupações éticas no conjunto da análise e é "realista" em sua ênfase sobre os interesses materiais por trás da ação humana, sobre a hipocrisia, a falsidade e o cinismo da vida política. Apesar de existirem paralelos surpreendentes em cada um dos projetos idealistas iniciados depois da Primeira Guerra Mundial - a Internacional Comunista e a Liga das Nações -, a utopia proposta pelo leninismo estava em clara oposição ao idealismo wilsoniano (HALLIDAY, 1999, p. 64-65).
}

É mister reconhecê-lo de uma vez para que o potencial valor heurístico proporcionado pela narrativa de 'grandes debates' - algo, per se, saudável em ciências sociais, de modo geral - não permaneça cerrado por uma Cama de Procusto desnecessária para o bom desenvolvimento da disciplina. E, assim como no mito grego, impedir que seja mutiladora da imaginação política e teórica em um momento histórico que exige dos estudiosos de RI alto grau de reflexividade e responsabilidade na prática do seu ofício: os ecos de 1914-1945 nas tensões internacionais atuais nos obrigam a isso (RIDDELL, 2014). Permitir que o campo das RI conheça mais sobre as contribuições marxistas de Rosa Luxemburgo acerca da 
guerra, da paz e demais temas internacionais é parte deste esforço crítico, pela vida e contra a repetição da barbárie que foi pano de fundo para o primeiro 'grande debate' de nossa disciplina.

Referências

ANGELL, N. A grande ilusão. $1^{a}$ ed. Brasília: Editora Universidade de Brasília, Instituto de Pesquisa de Relações Internacionais; São Paulo: Imprensa Oficial do Estado de São Paulo, 2002.

ASHWORTH, L. Did the Realist-Idealist Great Debate Really Happen A Revisionist History of International Relations". International Relations, v.16, n. 33, 2002.

BANKS, M. The inter-paradigmatic debate. In: LIGHT, M.; GROOM, A. International Relations: a handbook of current theory. London: Frances Printer, 1985.

BESANCENOT, O.; LÖWY, M. Rosa Luxemburgo (1870-1919). In: BESANCENOT, O.; LÖWY, M Afinidades revolucionárias: Nossas estrelas vermelhas e negras - Por uma solidariedade entre marxistas e libertários. $1^{\mathrm{a}}$ Ed. São Paulo: Ed. Unesp, 2016.

BOOHT, K. Security in anarchy: Utopian realism in theory and practice. International Affairs, vol. $67, \mathrm{n}^{\circ} 3,1991$.

BOOTH, K. 75 years on: rewriting the subject's past - Reinventing its future. In: BOOTH, K.; SMITH, S.; ZALEWSKI, M (eds.). International theory: positivism and beyond. Cambridge: Cambridge University Press, 1996.

CARR, E. The Twenty Year's Crisis (1919-1939): An Introduction to the Study of International Relations. London: Perennial, 2001.

COX, R. Social forces, states and world orders: beyond international relations theory. Millennium: Journal of International Studies, vol. 10, $\mathrm{n}^{\circ} 2,1981$.

FOUCAULT, M. Microfísica do Poder. Rio de Janeiro: Ed. Graal, 1979.

GONÇALVES, W.; SILVA, G. Dicionário de relações internacionais. 2 ed. Barueri, SP: Manole, 2010.

HALLIDAY, F. Repensando as relações internacionais. Porto Alegre: Ed. da Universidade/ UFRGS, 1999

HERZ, J. Idealist Internationalism and the security dilemma. World Politics, vol. 2, n² 1950.

HOBSBAWN. E. A era dos extremos: o breve século XX (1914-1991). São Paulo: Companhia das Letras, 1995.

HOBSBAWM, E. A era dos impérios (1875-1914). Rio de Janeiro: Paz e Terra, 1988.

HOFFMAN, S. An American social science: International Relations. Deadalus, vol. 106, nº 3 , 1977.

HOSCHILD, A. To end all wars: a story of loyalty and rebellion (1914-1918). Boston and New York: Hougton Mifflin Harcourt, 2011.

LAPID, Y. The third debate: on the prospects of International Theory in a Post-Positivist Era. International Studies Quarterly, vol. 33, nº 3, 1989.

LOUREIRO, I. A menos Eurocêntrica de todos: Rosa Luxembrgo e a acumulação primitiva permanente. In: SCHÜTRUMPF, J. (org.). Rosa Luxemburgo ou o preço da liberdade. $2^{a}$ ed. São Paulo: Fundação Rosa Luxemburgo, 2015.

LOUREIRO, I. Nota biográfica. In: Rosa Luxemburgo: Textos escolhidos - volume 1 / organização: Isabel Loureiro. São Paulo: Editora Unesp, 2011.

LUXEMburgo, R. A Acumulação do Capital. $3^{\text {a }}$ ed. Rio de Janeiro: Zahar, 1970.

LUXEMBURGO, R . A paz, a Tríplice Aliança e nós. In: Rosa Luxemburgo: Textos escolhidos - volume 1 / organização: Isabel Loureiro. São Paulo: Editora Unesp, 2011a.

LUXEMBURGO, R. Discurso de defesa em 20 de fevereiro de 1914. In: Rosa Luxemburgo: Textos escolhidos - volume 1 / organização: Isabel Loureiro. São Paulo: Editora Unesp, 2011b.

LUXEMBURGO, R. Marrocos. In: Rosa Luxemburgo: Textos escolhidos - volume 1 / organização: Isabel Loureiro. São Paulo: Editora Unesp, 2011c.

LUXEMBURGO, R. Novamente a massa e o líder. In: Rosa Luxemburgo: Textos escolhidos: volume 1 / organização: Isabel Loureiro. São Paulo: Editora Unesp, 2011d. 
LUXEMBURGO, R. O que queremos? In: Rosa Luxemburgo: Textos escolhidos - volume 1 / organização: Isabel Loureiro. São Paulo: Editora Unesp, 2011e.

LUXEMBURGO, R. Reforma social ou revolução? In: Rosa Luxemburgo: Textos escolhidos - volume 1 / organização: Isabel Loureiro. São Paulo: Editora Unesp, 2011f.

MARCOBELLI, E. Pre-war Socialist Pacifism. DANIEL, U. et al (eds.) International Encyclopedia of the First World War. Berlin: Freie Universität Berlin, 2014.

MEARSHEIMER, J. E.H. Carr vs. Idealism: The Battle rages on. International Relations, vol. $19, \mathrm{n}^{\mathrm{o}} 2,2005$.

NOGUEIRA, J.; MESSARI, N. Teoria das relações internacionais: correntes e debates. Rio de Janeiro: Campus, 2005.

QUIRK, J.; VIGNESWARAN, D. International Relations' first great debate: Context and Tradition. Canberra: Australian National University/RSPAS, 2004.

RIDDELL, J. Responding to Capitalist Global Disaster: 1914 and today. The Bullet: socialist project, E-Bulletin, n 1024 , August 2014.

SCHMIDT, B. The political discourse of anarchy: A disciplinary history of international relations. Albany: State University of New York Press, 1998.

SCHÜTRUMPF, J. (org.). Rosa Luxemburgo ou o preço da liberdade. $2^{\mathrm{a}}$ ed. São Paulo: Fundação Rosa Luxemburgo, 2015.

SMITH, S. The self-images of a discipline: A genealogy of international relations. In BOOTH, K.; SMITH, K. (eds.). International relations theory today. Cambridge: Polity Press, 1995.

THIES, C. Progress, history and identity in international relations theory: the case of the idealist-realist debate. European Journal of International Relations, vol. 8, no 2, 2002.

WALTZ, K. Man, the State and War: a theoretical analysis. New York: Columbia University Press, 2001.

WEAVER, O. The rise and fall of the inter-paradigmatic debate. In SMITH, S.; BOOTH, K.; ZALEWSKI, M (Eds.). International Relations: positivism and beyond. Cambridge: Cambridge University Press, 1996.

WEAVER, O. The sociology of a not so international discipline: American and European findings in international relations. International Organization, vol. 52, nº 4, 1998.

WILSON, P. The Myth of the First Great Debate. Review of International Studies, vol. 24, $\mathrm{n}^{\circ}$ 5 (special issue), 1998.

WILSON, P. Where are we now in the Debate about the First Great Debate? In: SCHMIDT, B. (ed.) International Relations and the First Great Debate. London: Routledge, 2012. 